\title{
CARACTERIZAÇÃO JUNTAS SOLDADAS POR CENTELHAMENTO EM TRILHOS FERROVIÁRIOS DE AÇO INTERMEDIÁRIO *
}

Gabriela Ribeiro Apolonio ${ }^{1}$

Daniel Andrade Paes Lima²

Rodrigo Rangel Porcaro 3

Geraldo Lúcio de Faria ${ }^{4}$

Elisângela Silva Pinto ${ }^{5}$

Luiz Cláudio Cândido 6

\begin{abstract}
Resumo
Juntas soldadas por centelhamento (flash butt welding) de trilhos de aço do tipo intermediário foram caracterizadas mecânica e estruturalmente. Além disso, ensaios preliminares de dilatometria foram aplicados ao metal base e correlacionados ao processo de soldagem. Os resultados indicam que o metal base atendeu aos requisitos da Norma AREMA (2013). A microestrutura de toda a região soldada é formada por perlita e os ciclos termomecânicos provocaram significativas alterações no tamanho das colônias perlíticas e na sua morfologia, com destaque às mudanças de espaçamento interlamelar em toda a junta e início de esferoidização na região de transformação parcial. Como consequência das alterações morfológicas da perlita, a microdureza foi significativamente reduzida na região de transformação parcial e refino de grãos. A taxa de resfriamento média após o processo de soldagem foi estimada a partir dos ensaios de dilatometria.
\end{abstract}

Palavras-chave: Trilhos; Soldagem por Centelhamento; Metalurgia da Soldagem.

\section{CHARACTERIZATION OF FLASH BUTT WELDED INTERMEDIATE STEEL RAILS Abstract}

Flash butt welded joints of an intermediate steel rail were characterized mechanically and structurally. Furthermore, preliminary dilatometry tests were applied to base metal and correlated to the welding process. Results indicate that the base metal was according to the requirements from AREMA standard (2013). The entire welded region microstructure is composed of perlite and significant changes in the perlite colonies size and its morphology was caused by thermomechanical cycles, and emphasizing the interlamellar spacing changes at the whole joint and beginning of spheroidization at the partial transformation region. As consequence of perlite morphological changes, microhardness was significantly reduced at the partial transformation region and grain refining. The average cooling rate after welding process was estimated by dilatometry tests.

Keywords: Steel Rails; Flash Butt Welding; Welding Metallurgy.

\footnotetext{
Engenheira Metalúrgica, Estudante, DEMET, UFOP, Ouro Preto, Minas Gerais, Brasil. Engenheiro Metalúrgico, Graduado, DEMET, UFOP, Ouro Preto, Minas Gerais, Brasil. Engenheiro Metalúrgico, MSc., Doutorando, REDEMAT, UFOP, Ouro Preto, Minas Gerais, Brasil. Físico, Dr., Professor DEMET, UFOP, Ouro Preto, Minas Gerais, Brasil.

Física, Dra., Professora IFMG Campus Ouro Preto, Ouro Preto, Minas Gerais, Brasil.

Engenheiro Metalúrgico, Dr., Professor, DEMET, UFOP, Ouro Preto, Minas Gerais, Brasil.
} 


\section{INTRODUÇÃO}

O transporte ferroviário geralmente é associado à alta produtividade e eficiência para movimentação de cargas em longas distâncias. A demanda crescente levou ao aumento da carga por eixo das composições e ao desenvolvimento de tecnologias de união dos trilhos para construção de linhas ferroviárias continuamente soldadas que permitem maior velocidade das composições [1].

O processo de soldagem elétrica por centelhamento (Flash Butt Welding) responde por mais de $90 \%$ de todas as soldas de trilhos no mundo [1]. Trata-se de um processo de união no estado sólido que emprega a resistência à passagem de corrente elétrica entre as duas superfícies dos trilhos para promover préaquecimento e fusão superficial. Uma vez atingida a temperatura de forjamento, aplica-se pressão que expulsa os líquidos formados e os óxidos, o que produz uma solda com qualidade geralmente superior àquela obtida por aluminotermia [2,3,4].

Segundo Mansouri e Monshi [2], a microestrutura da junta soldada por centelhamento é formada por três regiões: (i) crescimento de grão; (ii) região dos grãos recristalizados, e; (iii) região parcialmente transformada. Saita et al. [5] complementam afirmando que na soldagem por centelhamento ocorrem danos acentuados em locais que são simétricos em relação à linha central da solda e que reduzem a dureza. Com base nesse fato, a zona de amolecimento da Zona Termicamente Afetada (ZTA) pode ser considerada uma região crítica para a integridade dos trilhos.

Welgrill et al. [6] monitoraram com termopares os ciclos térmicos desenvolvidos na soldagem por centelhamento em trilhos ferroviários e obtiveram a temperatura máxima na alma superior a $1400^{\circ} \mathrm{C}$ e taxas de resfriamento entre $800^{\circ} \mathrm{C}$ e $500^{\circ} \mathrm{C}$ na ordem de $1^{\circ} \mathrm{C} / \mathrm{s}$ em todas as seções de um trilho com perfil TR-60.

Neste trabalho, juntas soldadas por centelhamento em um trilho ferroviário do tipo intermediário foram caracterizadas mecanicamente e estruturalmente em comparação ao metal base. Os efeitos do processo de soldagem nas propriedades do material foram relacionados a alguns modos de falha relatados para esse tipo de junta.

\section{MATERIAIS E MÉTODOS}

\subsection{Material}

O material analisado é um aço do tipo intermediário em trilhos TR-57 $(57 \mathrm{~kg} / \mathrm{m})$. O aço tipo intermediário é uma classe definida pela Norma AREMA [7], cujas especificações de propriedades mecânicas são apresentadas na Tabela 1.

Foram caracterizados 0 metal base e as juntas soldadas, cujos principais parâmetros de soldagem são apresentados na Tabela 2. A análise química do metal base foi realizada utilizando-se espectrometria de emissão óptica.

Tabela 1. Especificações de propriedades mecânicas para trilhos intermediários. Adaptado de AREMA (2013)

\begin{tabular}{c|c}
\hline Propriedade & Valor mínimo requerido \\
\hline Dureza superficial (HB) & 325 \\
\hline Limite de escoamento (MPa) & 551 \\
\hline Limite de resistência (MPa) & 1013 \\
\hline Alongamento (\%) & 10 \\
\hline
\end{tabular}


Tabela 2. Parâmetros de soldagem por centelhamento controlados para o trilho intermediário TR-57

\begin{tabular}{l|c|c}
\multicolumn{1}{c|}{ Parâmetro controlado na soldagem } & \multicolumn{2}{c}{ Valores } \\
\hline Intensidade e duração do flash inicial & $77,4 \mathrm{kA}$ & $20 \mathrm{~s}$ \\
\hline $\begin{array}{l}\text { Número de pulsos de corrente de pré-aquecimento e duração dos } \\
\text { pulsos }\end{array}$ & $10 \mathrm{un}$. & $3,8 \mathrm{~s}$ \\
\hline Intensidade dos pulsos de pré-aquecimento & $45-70 \mathrm{kA}$ & - \\
\hline Intensidade e duração do flash final & $38,3 \mathrm{kA}$ & $14,4 \mathrm{~s}$ \\
\hline Intensidade da força de recalque & $477 \mathrm{kN}$ & - \\
\hline Curso total após recalque & $37-45 \mathrm{~mm}$ & - \\
\hline
\end{tabular}

\subsection{Caracterização Estrutural}

Para a análise do metal base e das juntas soldadas foi aplicada a técnica de micrografia e a preparação das amostras metalográficas seguiu os procedimentos usuais. As seções de corte para caracterização estrutural das juntas soldadas são ilustradas na Figura 1.

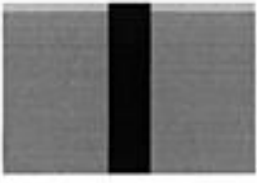

(a)

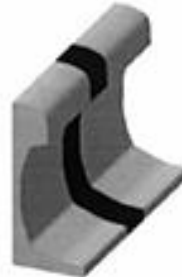

Figura 1. Seções de corte para caracterização metalográfica. Adaptado [2].

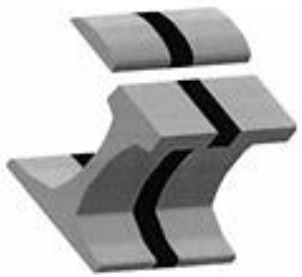

(b)

Para caracterização das colônias perlíticas, a seção de corte do boleto representada por (b) na Figura 1 foi utilizada, com corte a $10 \mathrm{~mm}$ abaixo da superfície de rolamento do trilho de modo a evitar a região endurecida oriunda do resfriamento acelerado aplicado na sua fabricação. As amostras do boleto soldado foram atacadas com Nital 2\% e avaliadas em Microscópio Óptico e Microscópio Eletrônico de Varredura (MEV). Microscopia de Força Atômica (MFA) foi aplicada para medida do espaçamento interlamelar perlítico em todas as regiões da ZTA: a $2 \mathrm{~mm}$ da linha central, região de crescimento de grão; a $8 \mathrm{~mm}$ da linha central, região de refino de grão; a 16mm da linha central, metal base. Foram utilizados 15 campos diferentes em cada região para medidas de espaçamento em grãos cujo corte metalográfico coincidiu com o plano transversal das lamelas perlíticas. As medidas de espaçamento a partir das imagens topográficas obtidas por MFA foram realizadas com auxílio do software Gwyddion.

Para medir o tamanho das colônias perlíticas, amostras do boleto soldado foram tratadas em forno com atmosfera controlada do Laboratório de Tratamentos Térmicos e Microscopia Óptica (LTM) do DEMET/UFOP a $700^{\circ} \mathrm{C}$, por $10 \mathrm{~min}$, o que corresponde a um ataque térmico sem austenitização. Foram obtidas cinco imagens de cada campo de interesse para as medidas. As imagens foram processadas pelo software LAZ, Leica versão 4.6, segundo a Norma ASTM E1382 [8].

\subsection{Ensaios Mecânicos}

Para avaliar a influência da soldagem na dureza em todo o perfil do trilho e comparálo com o metal base, foi feito um corte conforme a seção (a) da Figura 1. Um perfil de dureza Brinell (esfera de 2,5mm e carga igual a 187,5kgf, ASTM E10[9]) foi traçado na horizontal, a $10 \mathrm{~mm}$ abaixo da superfície, com distância entre pontos igual a 3mm. Ainda conforme a ilustração (a) da Figura 1, foi traçado outro perfil de 
dureza Brinell na vertical com a finalidade de observar eventuais variações da dureza ao longo das 3 regiões do trilho (alma, boleto e patim). Este perfil foi traçado a 3mm de distância da linha central da ZTA, com distância entre os pontos igual a $5 \mathrm{~mm}$. O perfil de microdureza foi obtido na seção (b) da Figura 1, a $10 \mathrm{~mm}$ abaixo da superfície do boleto. Utilizou-se a microdureza Vickers, com carga de $100 \mathrm{kgf}$ e tempo de penetração de 10 segundos, distância entre endentações igual a 0,5mm.

Para os ensaios de tração foram empregados corpos de prova segundo a Norma ASTM E8M [10], sendo 3 corpos de prova do metal base e 3 corpos de prova da junta soldada, cujas dimensões são apresentadas na Figura 2. A região útil utilizada foi maior que a largura total da ZTA (cerca de $35 \mathrm{~mm}$ ). Todos os corpos de prova foram usinados a partir de boletos, no sentido longitudinal e a $10 \mathrm{~mm}$ abaixo da superfície. Os corpos de prova referentes à solda foram atacados com Nital 2\% para garantir que toda a extensão da ZTA estaria na região útil (Figura 2 (b)).

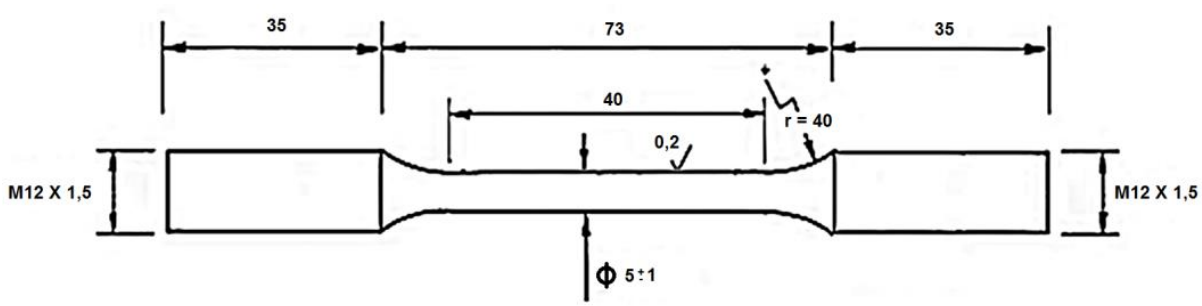

(a) Dimensões dos corpos de prova $(\mathrm{mm})$

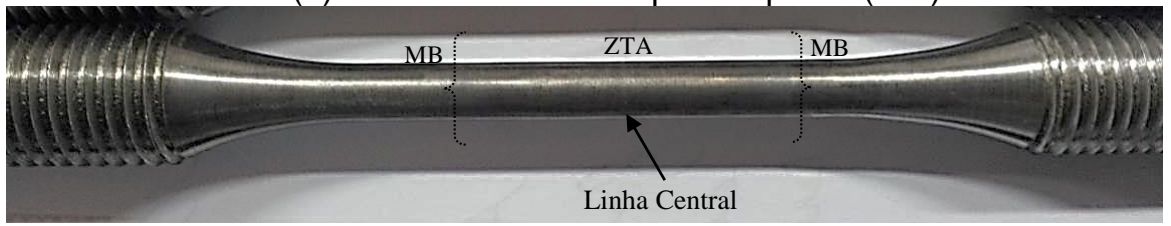

(b) Corpos de prova para ensaio de tração atacados com Nital 2\%

Figura 2. Corpos de prova para ensaios de tração. (a) Dimensões dos corpos de prova; (b) Corpo de prova de junta soldada atacado com Nital $2 \%$ evidenciando-se a linha central e a ZTA.

\subsection{Ensaios de Dilatometria}

Os corpos de prova para dilatometria foram usinados no metal base, sentido longitudinal do trilho e a $10 \mathrm{~mm}$ da superfície de rolamento do boleto. Os corpos de prova possuem seção cilíndrica com $3 \mathrm{~mm}$ de diâmetro e $10 \mathrm{~mm}$ de comprimento, conforme ilustrado na Figura 3, na qual pode-se observar também um termopar do tipo K soldado na sua superfície.

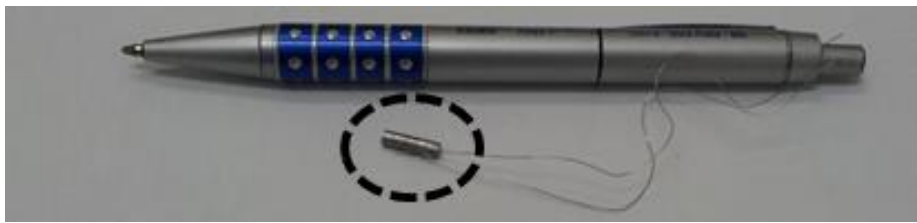

Figura 3. Corpo de prova de dilatometria (tracejado) usinado a partir de aço de trilho com termopar do tipo K soldado na superfície.

Os ensaios de dilatometria foram realizados em um dilatômetro R.I.T.A. L78 do LTM. A temperatura de austenitização definida foi $900^{\circ} \mathrm{C}$, considerando que o aço é aproximadamente eutetóide. Os ciclos térmicos aplicados são apresentados na Figura 4. Os corpos de prova passaram por análise metalográfica para confirmar eventos obtidos nos ciclos térmicos e para comparação à junta soldada. Aplicou-se ainda microdureza Vickers nos corpos de prova de dilatometria. 


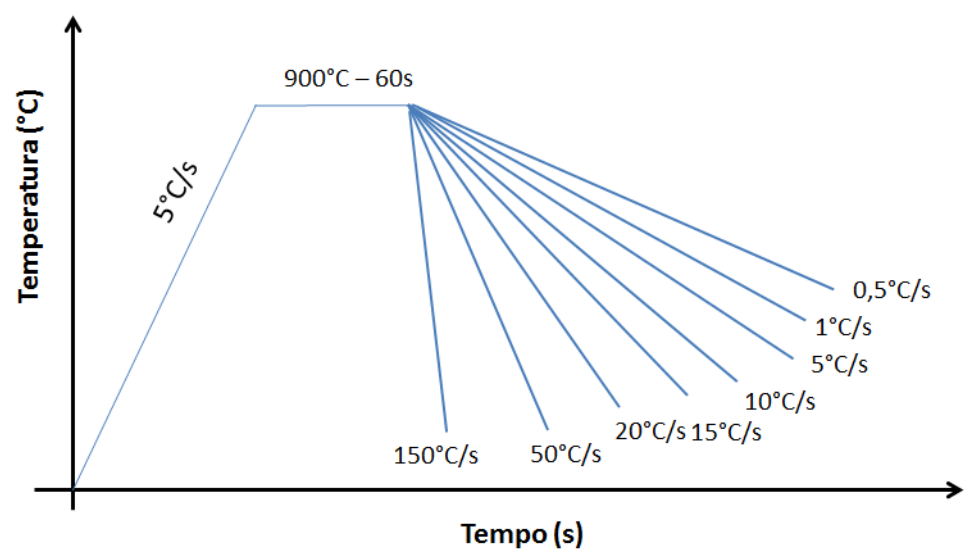

Figura 4. Ciclos térmicos aplicados em corpos de prova do metal base em ensaios de dilatometria.

\section{RESULTADOS E DISCUSSÃO}

\subsection{Análise Química e Caracterização Estrutural}

Os resultados de composição química do metal base são apresentados na Tabela 3, os valores estão dentro das faixas especificadas pela Norma AREMA [7].

Tabela 3. Resultado de composição química do metal base

\begin{tabular}{c|c|c|c|c|c|c|c|c|c|c}
\hline & \multicolumn{10}{c}{ Elemento (\% em massa) } \\
\hline & $\mathbf{C}$ & $\mathbf{M n}$ & $\mathbf{S i}$ & $\mathbf{P}$ & $\mathbf{S}$ & $\mathbf{C r}$ & $\mathbf{M o}$ & $\mathbf{N i}$ & $\mathbf{V}$ & $\mathbf{N b}$ \\
\hline Média & 0,715 & 0,843 & 0,240 & 0,016 & 0,008 & 0,078 & 0,009 & 0,012 & 0,002 & 0,004 \\
\hline
\end{tabular}

Esperava-se uma maior relação $\mathrm{Mn}-\mathrm{C}$ devido ao teor de carbono relativamente baixo, uma vez que o Manganês tem como característica a expansão do campo austenítico e a redução da temperatura eutetóide, o que reduz a formação de ferrita pró-eutetóide [11]. Devido ao teor de Mn relativamente baixo, ferrita pró-eutetóide foi observada no metal base, conforme será apresentado posteriormente.

Por meio de micrografias foi possível observar as 3 principais regiões que constituem a ZTA, sendo elas a zona de transformação parcial, a zona de refino de grão e a de crescimento de grão, e compará-las com o metal base, Figura 5. O processo de soldagem por centelhamento promove recristalização dinâmica, uma vez que envolve deformação [2]. A região de crescimento de grãos é aquela que possui temperatura de pico suficiente para promover o crescimento de grão austenítico após a recristalização, tal crescimento diminui à medida que se afasta da linha central até que a recristalização da austenita dá origem à perlita mais refinada, região de refino de grão (c) na Figura 5. Um esquema com todas as regiões da junta é apresentado na Figura 6. Na Figura 5 (d) evidencia-se a presença significativa de ferrita livre na linha central da solda devido à descarbonetação, fenômeno comum nesse tipo de processo e que geralmente não representa um problema por ser uma região muito pequena $[4,12,13]$. 

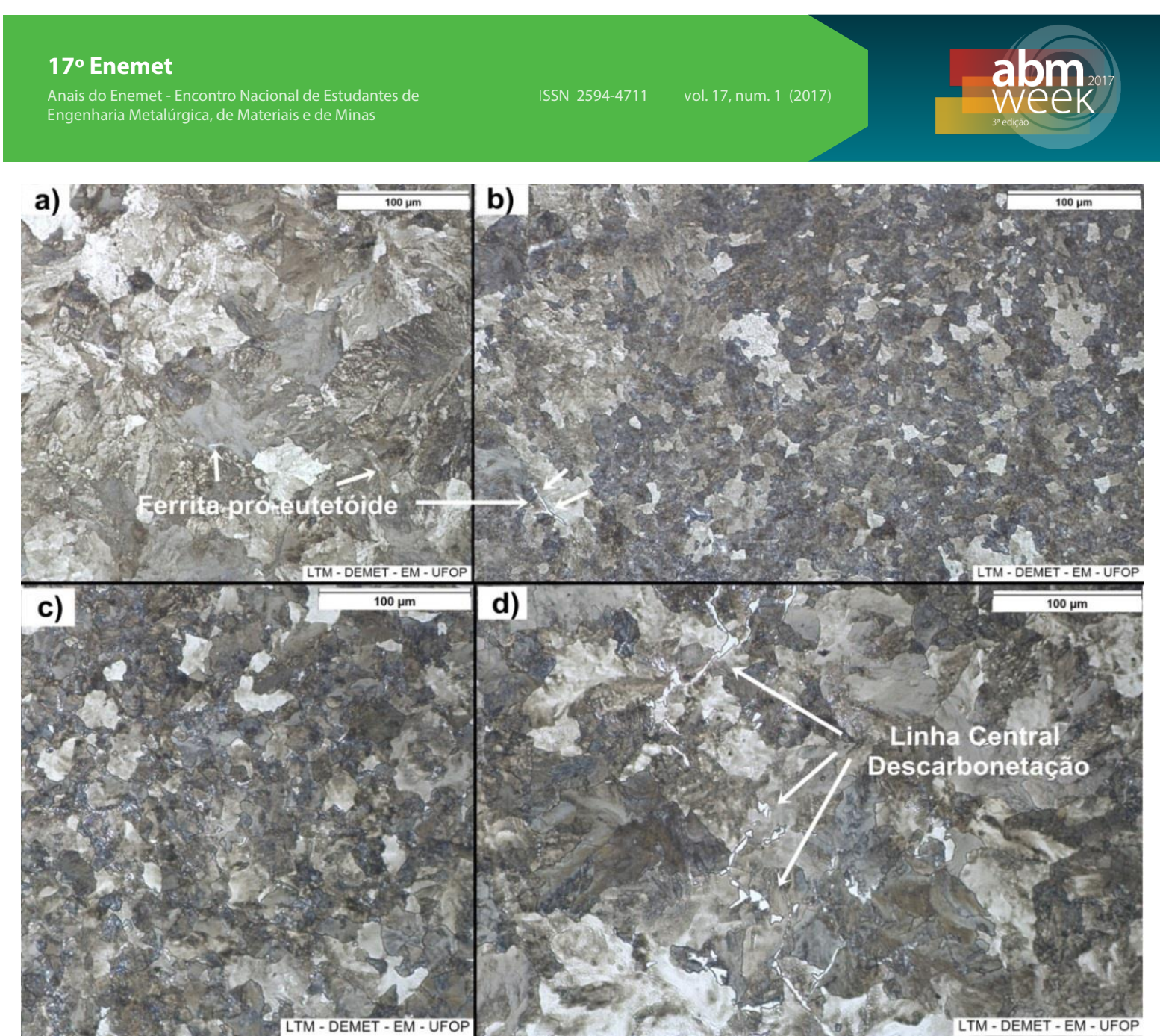

Figura 5. Micrografias de todas as regiões da ZTA no boleto de trilho soldado. (a) Metal Base com destaque para ferrita pró-eutetóide; (b) Transição entre MB/Transformação Parcial/Refino de Grão; (c)

Refino de Grão; (d) Crescimento de Grão e linha central com descarbonetação. Ataque: Nital 2\%, aumento original de 200x.

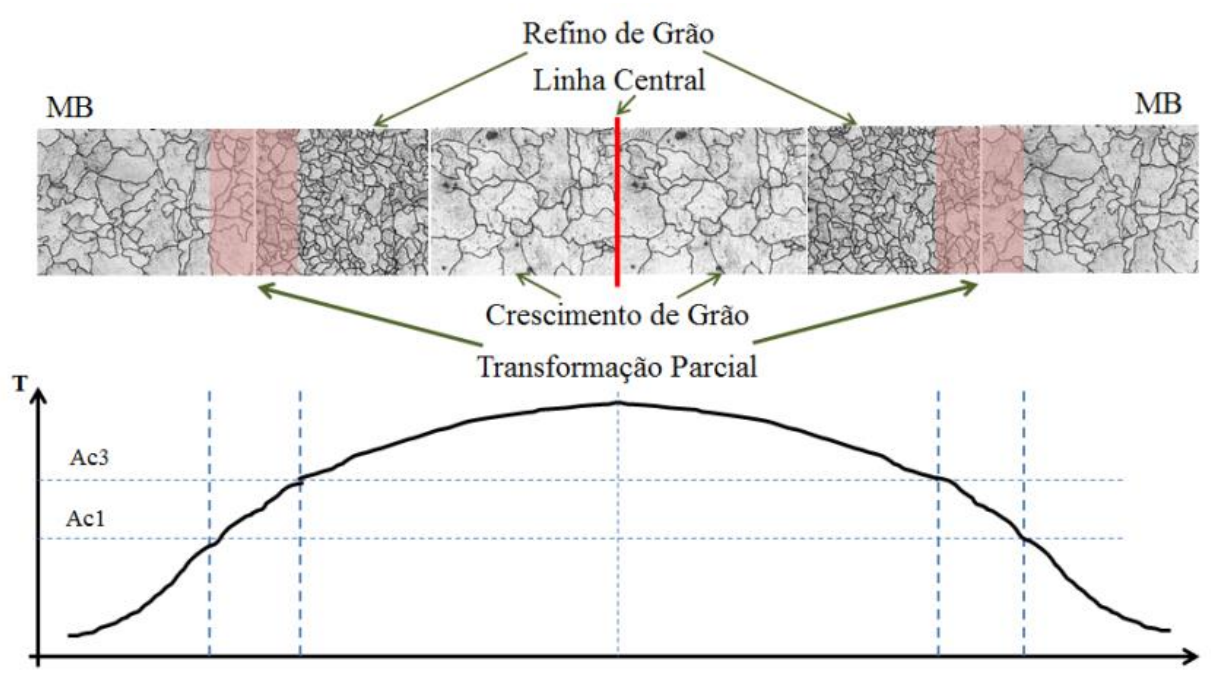

Figura 6. Figura esquemática relacionando a temperatura de pico e as diversas microestruturas das regiões da junta.

A microestrutura da região de crescimento de grãos da ZTA após ataque térmico para revelar os contornos das colônias de perlita é ilustrada na Figura 7 (a) após processamento de imagem. Na Figura 7 (b) apresenta-se a relação entre as cores dos grãos com a distribuição em função dos tamanhos (número de grão ASTM). A mesma análise foi realizada nas outras regiões da ZTA e os resultados são apresentados como diâmetro circular equivalente na Tabela 4. 


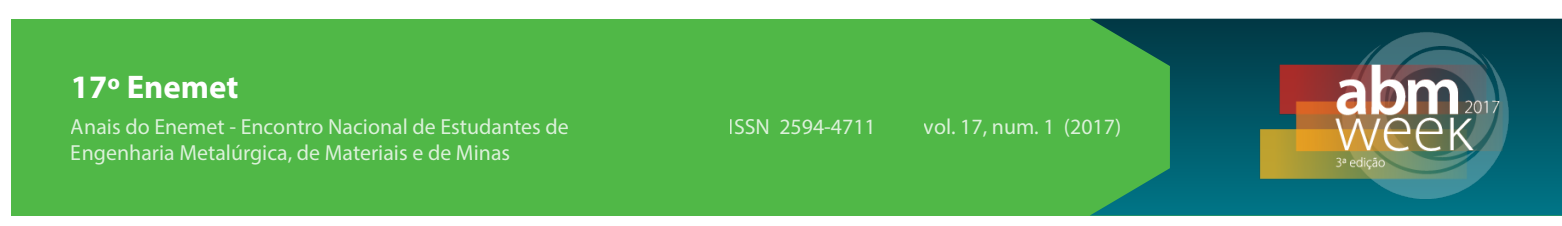

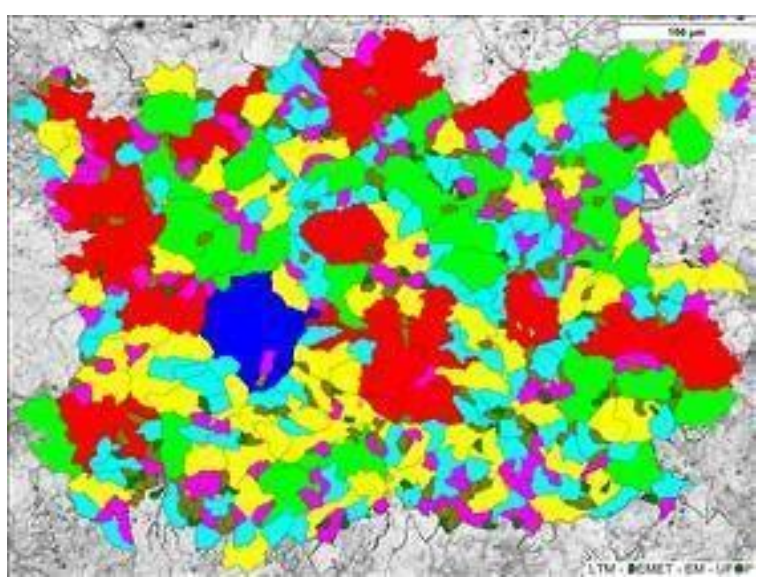

(a) Microestrutura da zona de crescimento de grãos evidenciando-se o tamanho dos grãos por diferentes colorações. 200x.

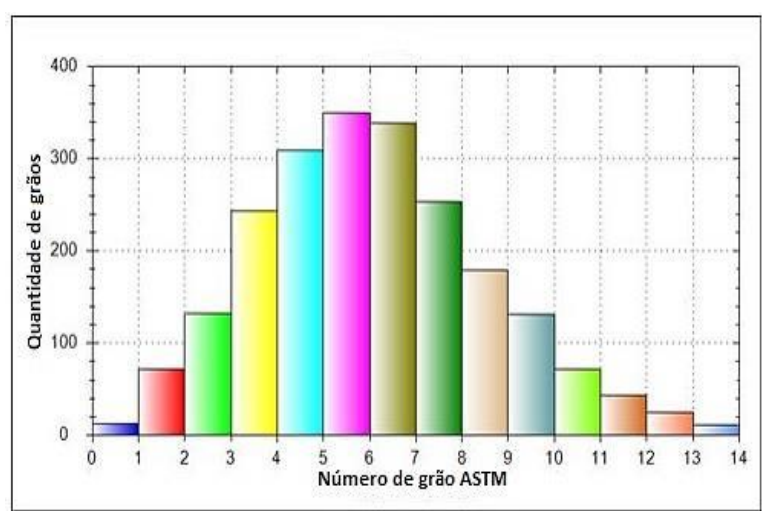

(b) Relação entre o número de grão ASTM, a quantidade de grãos e as diferentes colorações.

Figura 7. Microestrutura da zona de crescimento de grãos evidenciando-se o tamanho dos grãos pelas diferentes colorações em um aço de trilho intermediário soldado por centelhamento. Aumento original de 200x.

Tabela 4. Medidas de tamanho médio de colônias perlíticas na região central do boleto em junta soldada. ( $C G$ - crescimento de grão, $R G$ - refino de grão e MB - metal base)

\begin{tabular}{c|c|c|c}
\hline \multirow{2}{*}{$\begin{array}{c}\text { Tamanho de grão (diâmetro circular } \\
\text { equivalente } \boldsymbol{\mu m} \text { ) }\end{array}$} & \multicolumn{3}{|c}{ Região da Junta (distância à linha central) } \\
\cline { 2 - 4 } Média & $\mathrm{CG}-2 \mathrm{~mm}$ & $\mathrm{RG}-8 \mathrm{~mm}$ & $\mathrm{MB}-16 \mathrm{~mm}$ \\
\hline Desvio Padrão & 44,9 & 9,2 & 17,4 \\
\hline
\end{tabular}

Mansouri e Monshi [2] reportaram tamanho de grão igual a 15,9um na região de refino de grãos em juntas de trilho soldadas por centelhamento de um aço microligado e tamanho de grão médio de $254 \mu \mathrm{m}$ na região de crescimento de grão próximo à linha central.

Imagens obtidas por MEV em todas as regiões da junta são apresentadas na Figura 8 e pode-se observar que a morfologia da perlita varia significativamente em toda a extensão da ZTA. Na região de refino de grãos (Figura 8 (b)) e, sobretudo, na região de transformação parcial (Figura 8 (c)), ocorre esferoidização parcial da cementita. A esferoidização parcial da cementita em função dos ciclos termomecânicos da soldagem por centelhamento e a consequente redução da dureza é um dos maiores desafios tecnológicos da soldagem de trilhos [14], pois é associada à deformação superficial localizada e nucleação de trincas por fadiga $[4,13]$. A morfologia das colônias perlíticas na região de crescimento de grãos (Figura 8 (a)) é a que mais se assemelha ao metal base (Figura 8 (d)), incluindo o espaçamento interlamelar, como será apresentado adiante. 


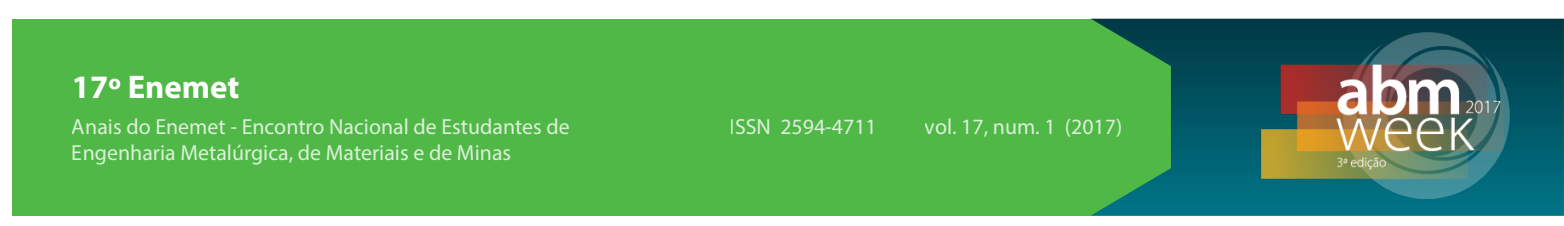

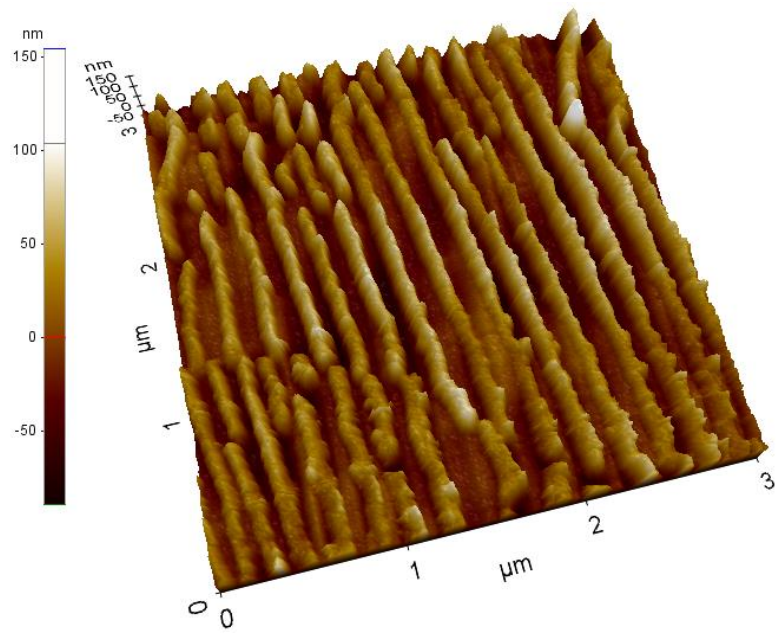

(a)

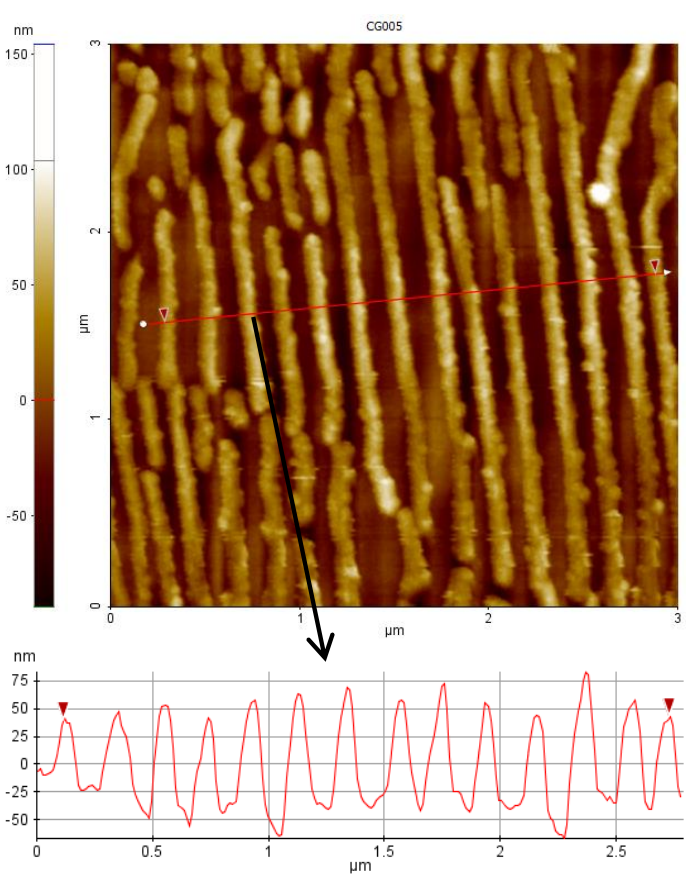

(b)

Figura 9. Microestrutura da região de crescimento de grãos na ZTA do boleto de trilho soldado por centelhamento (a). (b) Perfil linear perpendicular às lamelas para medida do espaçamento interlamelar perlítico.

\subsection{Ensaios Mecânicos}

Os resultados dos perfis de dureza Brinell na horizontal e vertical da junta soldada são apresentados na Figura 10 (a) e (b), respectivamente. A menor dureza corresponde à zona de transformação parcial e uma parte da zona de refino de grão. Portanto, a queda de dureza nessa região já era esperada devido à globulização parcial da cementita na perlita, resultado também reportado por outros autores $[1,2,12-14]$. Em relação ao perfil de dureza vertical, Figura 10 (b), percebe-se que os valores obtidos não variaram nas regiões do trilho. Mansouri e Monshi [2] encontraram valores de dureza mais altos na região da alma, quando comparado com a mesma região para o boleto e o patim. Este resultado foi associado à maior área superficial e menor espessura da alma, o que resultaria em uma maior taxa de resfriamento. As diferenças entre estes resultados podem estar associadas à composição dos aços, uma vez que os autores [2] utilizaram aço microligado.

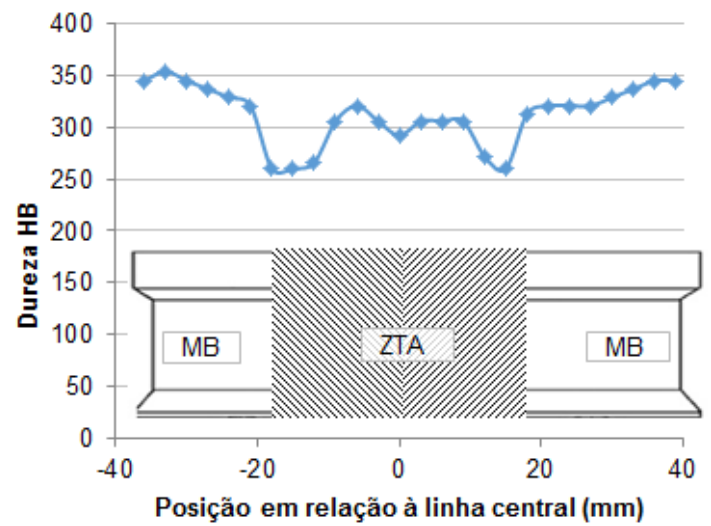

(a)

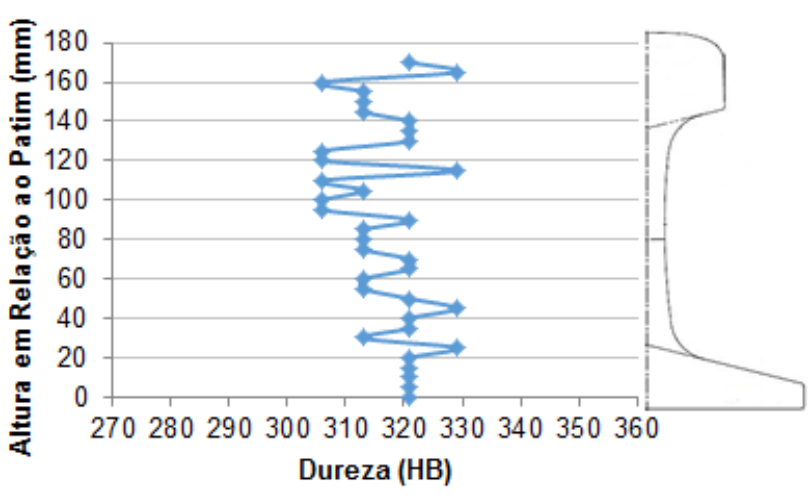

(b)

Figura 10. Perfis de dureza Brinell na horizontal (a) em relação à linha central da junta de trilho soldada e variação da dureza em relação ao patim (b) a 3mm da linha central. 
Os resultados de microdureza Vickers apresentados na Figura 11 são coerentes com as microestruturas obtidas em microscópio óptico, MEV e MFA, sendo as zonas de menor dureza equivalentes àquelas onde foram verificadas as maiores alterações na morfologia da perlita. Observa-se também que os valores de microdureza da região de crescimento de grãos é a que mais se aproxima da microdureza do metal base, estes resultados são atribuídos ao espaçamento interlamelar semelhante e à ausência de esferoidização da perlita na região de crescimento de grãos.

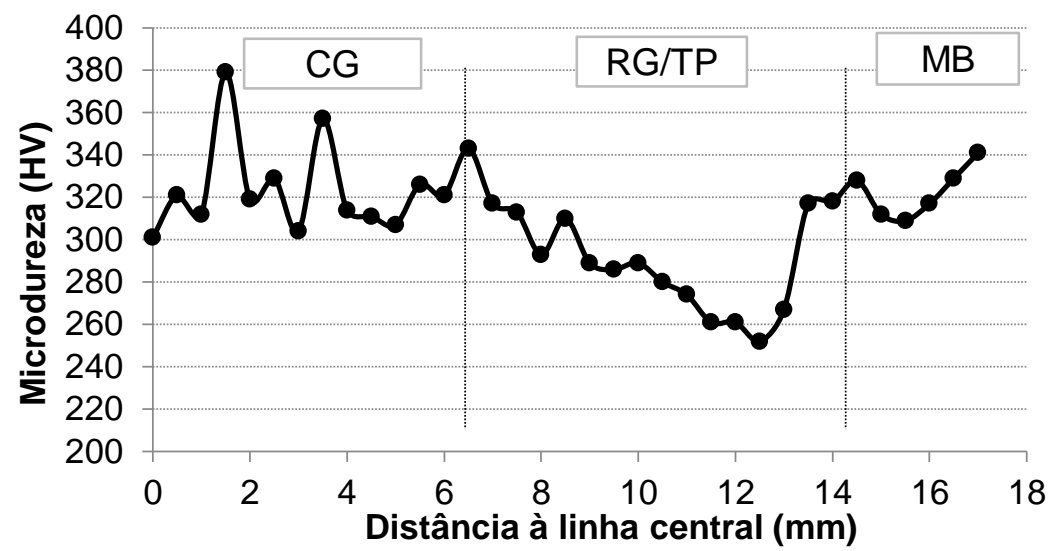

Figura 11. Perfil de microdureza Vickers na região central do boleto de junta soldada por centelhamento. CG crescimento de grãos; RG/TG - Refino de grãos/transformação parcial; MB Metal Base.

Os resultados dos ensaios de tração são apresentados na Tabela 6, na qual MB corresponde a corpos de prova do metal base e $\mathrm{S}$ a corpos de prova com soldas. Os valores de limite de escoamento, limite de resistência e alongamento do metal base atenderam aos requisitos da Norma AREMA [7]. Em relação às juntas soldadas, observou-se redução no limite de escoamento e limite de resistência, resultados semelhantes aos obtidos por Godefroid et al. [12]. Ressalta-se ainda que todos os corpos de prova de juntas fraturaram na região de transformação parcial, entre $10 \mathrm{~mm}$ e $12 \mathrm{~mm}$ da linha central, fato que se relaciona com a significativa modificação morfológica da perlita já discutida anteriormente.

Tabela 6. Resultados de ensaios de tração do metal base e de juntas soldadas. MB corresponde a corpos de prova do metal base e $\mathrm{S}$ a corpos de prova com soldas

\begin{tabular}{c|c|c|c}
\hline $\begin{array}{c}\text { Corpo de } \\
\text { Prova }\end{array}$ & $\begin{array}{c}\text { Limite de Escoamento } \\
(\mathrm{MPa})\end{array}$ & $\begin{array}{c}\text { Limite de Resistência } \\
(\mathrm{MPa})\end{array}$ & Alongamento (\%) \\
\hline MB Média & $1069 \pm 15$ & $1141 \pm 28$ & $8 \pm 2$ \\
\hline S Média & $941 \pm 22$ & $957 \pm 20$ & $9 \pm 1$ \\
\hline
\end{tabular}

\subsection{Dilatometria}

Os resultados dos ensaios de dilatometria em diferentes taxas de resfriamento são apresentados na forma de diagrama TRC na Figura 12, para temperatura de austenitização igual a $900^{\circ} \mathrm{C}$, ressalta-se que para taxas de resfriamento a partir de $15^{\circ} \mathrm{C} / \mathrm{s}$ há transformação martensítica no aço. 


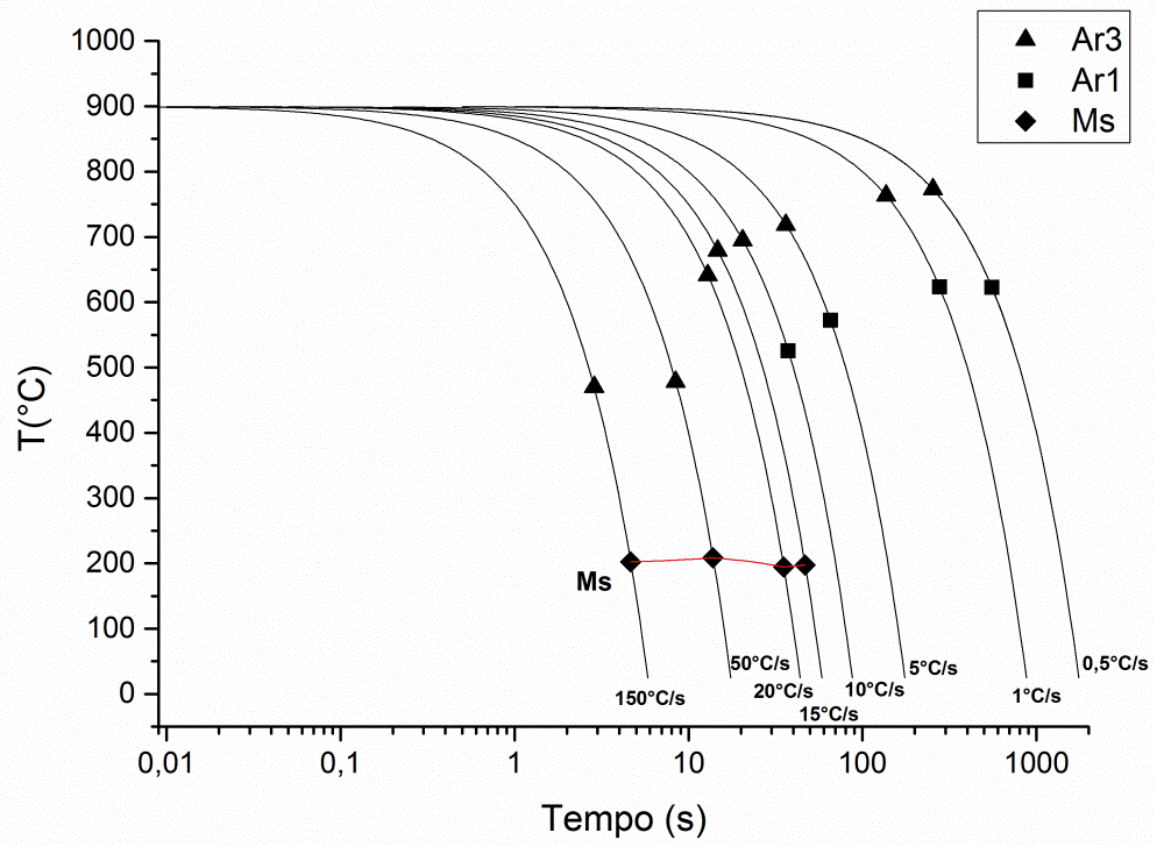

Figura 12. Diagrama de transformação em resfriamento contínuo do metal base para temperatura de austenitização igual a $900^{\circ} \mathrm{C}$.

A partir de medidas de microdureza Vickers nos corpos de prova de dilatometria, Tabela 7 , pode-se observar que a taxa de resfriamento igual a $1^{\circ} \mathrm{C} / \mathrm{s}$ foi a que apresentou dureza mais próxima àquela medida na região de crescimento de grãos (Figura 11). Portanto, é provável que a taxa de resfriamento após a soldagem por centelhamento tenha sido em torno de $1^{\circ} \mathrm{C} / \mathrm{s}$, semelhante ao reportado em estudo recente para trilho com perfil semelhante soldado por centelhamento [6]. Ressalta-se que é preciso realizar novos ensaios de dilatometria com diferentes temperaturas de austenitização para verificar a influência deste parâmetro sobre o tamanho de grão austenítico e sobre o diagrama TRC do aço para correlacionar ao processo de soldagem.

Tabela 7. Microdureza Vickers em corpos de prova de dilatometria

\begin{tabular}{c|c|c|c|c|c|c|c|c}
\hline & \multicolumn{7}{|c}{ Taxa de resfriamento $\left({ }^{\circ} \mathrm{C} / \mathrm{s}\right)$} \\
\hline & $\mathbf{0 , 5}$ & $\mathbf{1}$ & $\mathbf{5}$ & $\mathbf{1 0}$ & $\mathbf{1 5}$ & $\mathbf{2 0}$ & $\mathbf{5 0}$ & $\mathbf{1 5 0}$ \\
\hline Média & 355,1 & 365,5 & 401,3 & 406,6 & 437,8 & 456,2 & 807,3 & 912,4 \\
\hline Desvio padrão & 10,5 & 12,3 & 27,7 & 27,7 & 12,1 & 37,7 & 120,5 & 40,4 \\
\hline
\end{tabular}

\section{CONCLUSÃO}

O metal base possui composição química e propriedades mecânicas que atendem à Norma AREMA (2013). No entanto, as juntas soldadas não atenderam às especificações mínimas de propriedades mecânicas.

As quedas de dureza observadas nas regiões de transformação parcial e refino de grãos da ZTA são devidas às alterações da morfologia da perlita, sobretudo esferoidização parcial e aumento do espaçamento interlamelar.

Apesar do maior tamanho de grão das colônias de perlita na região de crescimento de grão, o espaçamento interlamelar perlítico foi menor que o medido na região de refino de grão. 
Os ciclos térmicos aplicados em ensaios de dilatometria e as respectivas propriedades mecânicas permitem estimar a taxa de resfriamento em torno de $1^{\circ} \mathrm{C} / \mathrm{s}$ na junta soldada.

\section{Agradecimentos}

Os autores agradecem à VLI pela doação do Material, ao IFMG Ouro Preto pelas análises em MFA e à FAPEMIG pelo apoio financeiro para participação no evento.

\section{REFERÊNCIAS}

1 Farhangi H, Mousavizadeh S. M. Horizontal Split-Web Fractures of Flash Butt Welded Rails. In: International Fracture Conference, 8th, 2007, Istanbul, Turquia, Anais. 2007. p. 509-517.

2 Mansouri H, Monshi A. Microstructure and Residual Stress Variations in Weld Zone fo Flash-Butt Welded Railroads. Science and Technology of Welding and Joining. v. 9, no 3, 2004, p. 237-246.

3 O'Brien RL (editor). Welding Handbook, Vol. 2: Welding Process, 9th ed. American Welding Society, Miame, FL. 2007.

4 Micenko P, Muruganant A, Huijun Li, Xiaofeng Xu. Double dip Hardness Profiles in Rail Weld Heat-Affected Zone - Literature and Research Review Report. Final Report, Project name: Improvements to Railway Welding. CRC for Rail Innovation, Brisbane, Australia, 2013.

5 Saita K, Ueda M, Yamamoto T, Karimine K, Iwano K, Hiroguchi K. Trends in Rail Welding Technologies and Our Future Approach. Yawata R\&D Lab, Kitakyushu City. p. 84-92. 2013. Report No. 105.

6 Weingrill L, Krutzler J, Enzinger N. Temperature Field Evolution During Flash Butt Welding of Railway Rails. Materials Sciente Forum, Switzerland, Trans Tech Publications, 2017; v. 879: 2088-2093.

7 Arema (American Railway Engineering and Maintenance-of-Way Association). Rail. Manual of Railway Engineering. v. 1, p. 695-965, 2013.

8 American Society For Testing And Materials, Philadelphia. E1382. Standard Test Methods for Determining Average Grain Size Using Semiautomatic and Automatic Image Analysis. 2015. 24 páginas.

9 American Society For Testing And Materials, Philadelphia. E 10 Standard Test Methods for Brinell Hardness of Metallic Materials. Philadelphia, 2009, 32 páginas.

10 American Society For Testing And Materials, Philadelphia. E 8M Standard Test Methods for Tension Testing of Metallic Materials. Philadelphia, 2008, 22 páginas.

11 Faria GL, Godefroid LB, Cândido LC, Porcaro RR. Caracterização Microestrutural e Estudo Cinético de Transformação de Fases em Dois Aços Standard e Premium de Aplicação Ferroviária. In: 710 Congresso Anual da ABM - Internacional, 2016, Rio de Janeiro. 710 Congresso Anual da ABM - Internacional. São Paulo: ABM, 2016. v. 71.

12 Godefroid LB, Faria GL, Cândido LC, Viana TG. Fatigue failure of a flash butt welded rail. Procedia Materials Science. p. 1896 - 1901. 2014.

13 Innotrack Integrated Project no. TIP5-CT-2006-031415. D4.6.1 - The influence of the working procedures on the formation and shape of the HAZ of flash butt and aluminothermic welds in rails. 2008.

14 Zerbst U, Lunden R, Edel K. O.; Smith, R. A. Introduction to the damage tolerance behaviour of railway rails - a review. Engineering Fracture Mechanics, v. 76, p. 25632601, 2009.

15 Silva ALVC, Mei PR. Aços e ligas especiais. 2. ed. Rev. amp., São Paulo: Blucher, 2006. $646 \mathrm{p}$. 